ISSN: 0213-2079 - ISSN electrónico: 2386-3889

DOI: https://doi.org/10.14201/shhmo20214314770

\title{
EL TRANSPORTE DE MADERAS PARA LOS DEPARTAMENTOS NAVALES ESPAÑOLES EN LA SEGUNDA MITAD DEL SIGLO XVIII ${ }^{1}$
}

\section{The transport of timbers for the Spanish naval departments in the second half of the 18th century}

\section{Rafal REICHERT}

Instituto de Estudios Ibéricos e Iberoamericanos, Universidad de Varsovia r.reichert@uw.edu.pl

ORCID: https://orcid.org/0000-0002-3462-8678

Fecha de recepción: 22/04/2020

Fecha de aceptación: 03/06/2021

RESUMEN: En este artículo se presenta uno de los aspectos poco conocidos en la historiografía española, que toca la organización logística de suministros de madera para los departamentos navales de España en la segunda mitad del siglo XVIII. Mediante el estudio de casos sobre transportes y fletes se puede observar su importancia desde los enfoques legislativo, operativo y práctico. Finalmente es posible presentar las diferencias en estrategias empleadas por el Estado borbónico para mantener constante suministro de materias primas provenientes del Báltico y de las Indias.

Palabras clave: siglo XVIII; Báltico; Nueva España; transporte; logística; asientos; Marina Real.

1. El presente artículo es producto del proyecto: The role of wood supplies from the southern Baltic region and the viceroyalty of New Spain in the development of Spanish seaborne empire in the eighteenth century, financiado por The National Science Center, Poland. Referencia: 2017/25/B/HS3/01017. 
ABSTRACT: This article presents one of the little-known aspects of the Spanish historiography, which deals with the logistical organization of wood supplies for the naval departments of Spain in the second half of the 18th century. It is importance that transport and freight can be analyzed from the legislative, operational and practical approaches. Finally, in this article is possible to present the differences in strategies used by the Bourbon State to maintain a constant supply of raw materials from the Baltic and the West Indies.

Keywords: 18th century; Baltic; New Spain; transportation; logistics; asientos; Royal Navy.

\section{INTRODUCCIÓN}

Las investigaciones que se han desarrollado en las primeras dos décadas del siglo XXI sobre la modernización del Estado borbónico, la movilidad de recursos y los asientos para el Ejército y la Marina son múltiples, abordando las temáticas desde diferentes enfoques historiográficos, metodológicos y teóricos. Los aspectos que más sobresalen en dichas aportaciones se centran en estrategias, proyectos y reformas tanto fiscales como administrativo-comerciales emprendidas por el Estado borbónico para recuperar el esplendor de las armas españolas, perdido durante los reinados de los últimos Habsburgo. La mayoría de los historiadores que trabajan el tema centran su atención en tres temas principales: la fiscalidad y el gasto en el mantenimiento de la máquina bélica; las reformas estructurales del Ejército y de la Marina; el fomento de la construcción naval y de las defensas costeras; y lo que supusieron estos cambios, tanto para el aparato gubernamental del Estado como para la sociedad, con la mira puesta en la actuación de los hombres de negocios, quienes a través de sus redes sociales y comerciales, tanto regionales como internacionales, aseguraban a España los suministros necesarios de materias primas para la Marina Real, que se convirtió en un sostén de la política imperialista de los Borbones españoles en la segunda mitad del siglo XVIII (Valdez-Bubnov, 2009 y 2018; Baudot Monroy, 2012; Díaz Ordoñez, 2009 y 2018; Rodríguez Hernández, Arroyo Vozmediano y Sánchez Belén, 2017; Solbes Ferri y Fé Cantó, 2016).

Últimamente ha surgido un nuevo camino en los estudios de historia militar y naval hispana donde los investigadores, mediante el análisis de los negocios y redes sociales que estableció el Estado borbónico a través del otorgamiento de asientos, intentan interpretar dichas dinámicas político-comerciales en el contexto de la globalización temprana (Torres Sánchez, 2013 y 2016; Serrano Álvarez, 2013 y 2019). El tema por su naturaleza es complejo, aunque sorprendente, y ha permitido observar 
las acciones y reacciones no tan solo a escala local, regional y estatal, sino también internacional y global. Una indiscutible contribución a ello, en torno al suministro de materias primas procedentes de diferentes puntos del mundo atlántico, son los trabajos que analizan la legislación de áreas forestales, contratos para piezas labradas, arboladuras y tozas, además de la extracción en los montes tanto peninsulares como de otras regiones (Aranda, 1990; North, 1996; Torrejón Chaves, 2000; Quintero González, 2004; Andrade Muñoz, 2006; Aragón Ruano, 2011, 2017 y 2019; Martínez González, 2013; Trindade, 2015; Wing, 2015; Reichert, 2016, 2019a y 2019b; López Arandia, 2018; Fernández Flórez, 2019). Sin embargo, no existen aportaciones sobre el transporte y la logística de suministros madereros para los arsenales reales. Por ello, en el presente artículo se pretenden analizar los transportes de cargamentos provenientes de diferentes regiones del mundo atlántico, para demostrar la importancia de una buena organización logística y el papel esencial de los asentistas en el mantenimiento de la fluidez constante de unos pertrechos navales tan necesarios para la construcción naval española y el mantenimiento de los buques de la Marina Real. Por esto, en esta aportación se pretende seguir dicho curso de la globalización temprana, centrándose en el ámbito, todavía poco conocido, de la organización de transportes de maderas, tanto a nivel legislativo como práctico, con la finalidad de beneficiar tanto a la Armada Real como a los proveedores privados, quienes actuaron como nexos entre diferentes regiones de España, Europa e Hispanoamérica.

Es importante subrayar que la investigación es apenas un primer acercamiento a este tema y todavía quedan preguntas por responder, no obstante, se espera a través del presente artículo impulsar el debate y mayor interés sobre el funcionamiento de transportes de materias primas, tan importantes en el desarrollo del poderío naval tanto de la España borbónica como de otras potencias europeas. Finalmente, la base archivística de la aportación se compone de los fondos de los archivos de España (General de Simancas e Histórico Provincial de Cádiz) México (General de la Nación) y Polonia (Estatal de Gdańsk y Archivo Central de Registros Históricos de Varsovia).

\section{LA LEGISLACIÓN EN TORNO AL TRANSPORTE Y APLICACIÓN DE LOS ASIENTOS}

Los asientos que otorga la Corona española a partir de la década de 1740 hasta finales del siglo XVIII muestran un patrón común donde se obligaba a los asentistas a entregar las maderas según dimensiones, características y calidades, en función de las solicitudes de los departamentos navales de El Ferrol, La Carraca y Cartagena. Uno de los puntos que a menudo aparece en los contratos es el relativo a la logística para garantizar y organizar el transporte de las piezas labradas, troncos y arboladuras, tanto fluvial como marítimo. 
Uno de los primeros ejemplos de dicha práctica es el asiento de Francisco Pugét y Agustín Gibert y Xurrich ${ }^{2}$, vecinos de Barcelona, quienes mediante su apoderado Jaime Planell solicitaron un contrato para extraer durante 12 años, diferentes piezas de madera de los bosques de Espot, Escalot, Escar, Boumort Carreu, Cellent, Perlas, Lluch y los montes de Tortosa. En los capítulos XII, XIV y XV del asiento aparecen las condiciones y obligaciones de cada parte que lo firma, sobre conducción y transporte de maderas. En el primer punto mencionado, los asentistas se comprometían a realizar por su «cuenta el embarco y conducción de dichos géneros a los arsenales de departamentos de Cartagena, Cádiz y Ferrol», sin embargo, el desembarque de dichos productos debería ser financiado por la Corona. En el mismo capítulo, los asentistas aseguraban que el tiempo de desembarque de las maderas no debía exceder de 20 días y, de no cumplir dicho plazo, recibirían de parte de la Real Hacienda 20 reales de plata de diez y seis cuartos por tonelada al mes ${ }^{3}$. En cambio, el punto XIV tocaba la cuestión de fletes de maderas y otros productos forestales, donde los asentistas pidieron ayuda oficial a la Corona, solicitando que «estén obligados los ministros de V.M. a embargar las embarcaciones, así españolas como extranjeras, que necesitase [el apoderado Jaime Planell], y que se hallen en cualquiera de los puertos, o plazas de los reales dominios de V.M. para el transporte de los géneros referidos [...] pagándoles los fletes que cuando se toman para el real servicio de V.M» ${ }^{4}$. Esta petición demuestra que los comerciantes catalanes no disponían de suficientes barcos para poder satisfacer la conducción de maderas. Esta tesis todavía se ve reforzada al analizar los datos que presentó Juan de Isla en su Extracto de las maderas de construcción alijadas en los diques de esta ensenada de Carranza [el Ferrol] desde el 14 de mayo de 1750 con expresión de las embarcaciones que las han conducido, sus capitanes y banderas de cuenta y riesgo ${ }^{5}$. Acercándose a los datos del movimiento marítimo recogidos en la Tabla 1 se ve con precisión que en los últimos años del asiento de Francisco Pugét y Agustín Gibert y Xurrich (1750-1752), la presencia de las embarcaciones catalanas es insignificante en comparación con las de otras regiones de España, Francia u hasta Holanda.

2. Archivo General de Simancas (AGS), Secretaría de Marina, libro 786 exp. titulado: Jaime Planell, vecino de esta corte, apoderado de don Francisco Pugét y don Agustín Gibert y Xurrich, que lo son de Barcelona, puesto a los pies de V.M. y deseoso de emplearse en el real servicio, se obliga en nombre de dichos a proveer en los departamentos de Cartagena, Cádiz y Ferrol, la arboladura, tablones y piezas cuadradas, brea negra y alquitrán para la Real Armada. Asiento firmado para el periodo de entre $1^{\circ}$ de enero de 1742 y 31 de diciembre de 1753 .

3. AGS, Secretaría de Marina, libro 786 exp. titulado: Jaime Planell..., f. 5.

4. AGS, Secretaría de Marina, libro 786 exp. titulado: Jaime Planell..., f. 5.

5. AGS, Tribunal Mayor de Cuentas de la Marina, legajo 4298. Cuentas. 
RAFAEL REICHERT

EL TRANSPORTE DE MADERAS PARA LOS DEPARTAMENTOS NAVALES ESPAÑOLES EN LA SEGUNDA MITAD DEL SIGLO XVIII

TAвLA. 1 Nacionalidad de barcos que realizaron viajes al arsenal de El Ferrol

\begin{tabular}{|c|c|c|c|c|c|c|c|c|c|}
\hline Fecha & España & Francia & Cataluña & Holanda & Portugal & Inglaterra & Dinamarca & Suecia & Total \\
\hline $\mathbf{1 7 5 0}$ & 83 & - & 1 & - & 1 & - & - & - & 85 \\
\hline $\mathbf{1 7 5 1}$ & 264 & 28 & 2 & 9 & 7 & 4 & 1 & 1 & 316 \\
\hline $\mathbf{1 7 5 2}$ & 672 & 91 & 5 & 9 & 2 & 3 & - & - & 782 \\
\hline $\mathbf{1 7 5 3}$ & 161 & 53 & 16 & 4 & - & 2 & - & - & 236 \\
\hline 1754 & 81 & 15 & 11 & 4 & 1 & 1 & - & - & $\begin{array}{c}113 \\
16\end{array}$ \\
\hline $\mathbf{1 7 5 5}$ & 6 & 1 & - & - & - & - & - & - & 7 \\
\hline $\mathbf{1 7 5 6}$ & 73 & - & - & - & 1 & - & - & - & 74 \\
\hline $\mathbf{1 7 5 7}$ & 79 & - & 1 & 1 & - & - & - & - & 81 \\
\hline $\mathbf{1 7 5 8}$ & 38 & - & 2 & 1 & - & - & - & - & 41 \\
\hline $\mathbf{1 7 5 9}$ & 10 & - & - & - & - & - & - & - & 10 \\
\hline $\mathbf{1 7 6 0}$ & 6 & - & - & - & - & - & - & - & 6 \\
\hline Total & 1473 & 188 & 38 & 28 & 12 & 10 & 1 & 1 & 1752 \\
\hline
\end{tabular}

Fuente: Archivo General de Simancas (AGS), Tribunal Mayor de Cuentas de la Marina, legajo $4298^{6}$.

Es importante aclarar que en la década de 1750, además de este asiento de los catalanes, también estaban vigentes los del propio Juan de Isla, quien representaba intereses vascos, y los de Melchor Cortés, Carlos Mas y Areñy, y Joseph Queralt, que actuaban en nombre de la casa comercial catalana Ruesga ${ }^{7}$. En la misma década, la Corona todavía firmó asientos con Pedro Asensio, quien se comprometió a extraer maderas de roble y encina de los montes andaluces ${ }^{8}$ y con los comerciantes holandeses Juan y Daniel Gildemeester o Gil de Meester, quienes desde Lisboa ofrecían su servicio de flete para llevar mercancías desde distintas regiones de Europa. Al ofrecer un precio bajo por servicio de transporte dichos neerlandeses prácticamente

6. Es un barco llamado La Misericordia, sin datos sobre su origen. Su capitán se llama Juan Bevidovich.

7. AGS, Secretaría de Marina, libro 786 exp. titulado: Don Juan Fermin de Barbaria, del consejo de su Majestad en el Tribunal de la Contaduría Mayor de Cuentas de Su Majestad, y contador de la guerra de la tesorería general. Asiento para los años entre 1742 y 1754.

8. AGS, Secretaría de Marina, libro 786 exp. titulado: Don Pedro Asensio, vecino de la ciudad de Cádiz, y asentista actual de maderas de roble y encina para la construcción y carena de los navíos de la Real Armada, [...] se encargará de la continuación del mismo asiento, no solo para proveer el referido material en el departamento de Cádiz, sino también en el de Cartagena. 
monopolizaron los suministros de maderas y materias primas forestales hasta los años 1760 (Torres Sánchez, 2013: 271). Este monopolio lo demuestran múltiples registros de los capitanes extranjeros que participaron: William Suget del navío inglés Blanket, Jacobo Meris de la urca holandesa San Pedro, Dirk Dirk de la urca holandesa Daniel, Dierk Boer de la urca holandesa Jacoba Gertrudis, Juan Breevilt del navío holandés Willemina, entre otros, quienes en los años 1752 y 1753, bajo la vigilancia de Eugenio de Mena, el apoderado de los Gildemeester, hicieron varios transportes de árboles, arboladuras y tablonería desde el Norte, pero también desde Tortosa y el Mediterráneo, bajo la responsabilidad de otro apoderado, Lorenzo de Mena9

Regresando al análisis del asiento de Pugét y Gibert y Xurrich, es muy interesante el capítulo XV donde los asentistas se comprometían, a pesar de los siniestros naturales y rapiñas piráticas, cumplir con su deber, señalando que «serán por mi cuenta los riesgos de navegación, por lo que mirasen a temporal y corsarios de Berbería; y aunque el valor de los géneros que se perdiesen por cualquier de estos motivos, no se me haya de satisfacer por la Real Hacienda, se me han de abonar dichos géneros en descargo de mi obligación, como si se hubiesen entregado» ${ }^{10}$. En el mismo punto, también se exponía la solución ante el estallido de guerras o represalias, sobre todo, por parte de Inglaterra y Holanda, que «pudiesen estorbar la navegación exacta», en la que los asentistas únicamente se comprometían a llevar los géneros del contrato al puerto de los Alfaques. En caso de ser apresadas embarcaciones transportistas durante su derrotero por alguna de las potencias enemigas de la Corona española, apuntaban que «se me deberán de bonificar en la misma conformidad que los entregados, y bajar igualmente de la obligación, como si se hubiesen recibido en almacenes y diques de los departamentos, debiendo hacer constar en cualquiera de los casos expresados el embarco de los referidos géneros, con los conocimientos o pólizas de cargo de los capitanes o patrones de las embarcaciones en que se hubiesen cargado y revisado por el ministro de V.M. residente en Tortosa, sin que se necesite de otro requisito para su abono» ${ }^{11}$.

Es interesante también analizar el primer asiento, que se celebró en 1749, de los mercaderes holandeses Gildemester. La fortaleza económico-comercial de los neerlandeses, les permitió recibir buenos beneficios frente a otros comerciantes, quienes suministraban a la Marina la materia prima. Con ello, en el capítulo I de su contrato, se aclara con rigidez que los transportes se realizarían únicamente desde los parajes a los cuales se enviaba la madera de los montes, hasta los arsenales, donde la descarga debía correr a cuenta de la Corona, en un plazo de ocho días desde el arribo de la embarcación, lo que a su vez obligaba a los intendentes de cada departamento

9. AGS, Secretaría de Marina, legajo 612, libro de Asientos, varios expedientes.

10. AGS, Secretaría de Marina, libro 786 exp. titulado: Jaime Planell..., f. 5.

11. AGS, Secretaría de Marina, libro 786 exp. titulado: Jaime Planell..., f. 5 y 5v. 
a trabajar con mayor esmero, al contrario que en el caso del contrato de Pugét y Gibert y Xurrich, en el que la descarga contaba con un plazo de 20 días, después de la llegada a los departamentos de Cartagena, El Ferrol y La Carraca. El capítulo IV demuestra que la Real Hacienda otorgó a los Gildemeester el beneficio de no cobrarles impuestos y aranceles a las embarcaciones nacionales y extranjeras que prestasen su servicio para transportar maderas, lo que influyó en el bajo costo de los fletes que ofrecía la compañía holandesa ${ }^{12}$. Todavía más interesantes son los dos siguientes asientos que firmaron los Gil de Meester en 1751. El primero se estableció para surtir los departamentos navales de Cartagena, El Ferrol y La Carraca con las maderas del Norte $^{13}$, y el segundo para transportar las maderas necesarias desde Guarnizo a Cartagena, con el fin de terminar la construcción de 6 fragatas ${ }^{14}$. Ambos contratos fueron de corto plazo, sin embargo permitieron a los asentistas fortalecer su posición en el sistema de suministros forestales, lo que les brindó un verdadero monopolio en dicho negocio en los años posteriores, en los que los Gildemeester recibieron asientos a largo plazo. Según apunta en su relación Eugenio de Mena de 1754, las compras se realizaban en varios lugares de la Península Ibérica y en Ámsterdam, Polonia, Prusia, Suecia y Noruega ${ }^{15}$. La tendencia de comprar madera del Báltico confirma la opinión de Antonio de Ulloa, quien cotejó el precio de la madera del Norte y sobre todo de arboladuras, en el asiento de 8 años que en 1752 firmaron los Gil de Meester como «de mucha conveniencia a la Real Hacienda» ${ }^{16}$. Esta apertura de España al mercado de recursos forestales provenientes del Báltico provocó la carrera por los pertrechos navales con otras potencias europeas, sobre todo con Gran Bretaña, Holanda y Francia.

Esta situación obligaba a los asentistas a establecer sus redes de contactos en los principales puertos del Norte donde especialmente aseguraron su posición en el comercio de maderas, mediante las colaboraciones con comerciantes de Ámsterdam, como por ejemplo la familia de banqueros y comerciantes dirigida por los hermanos Thomas y Adrián Hope, quienes colaboraban tanto con los contratistas como con los cónsules españoles en la adquisición de maderas y fletes en el Báltico. Ellos enviaban las solicitudes para comprar en Riga tablazón, arboladura, tozas y cáñamo

12. AGS, Secretaría de Marina, libro 787 exp. titulado: Don Eugenio de Mena a los Rs. Ps. de V.M. dice como apoderado de D. Juan y D. Daniel Gil de Meester, y a nombre de ellos, que en la consideración [...] por formal contrata [de] la conducción de las maderas de construcción para la fábrica de navíos [...], f. 36 y 36v.

13. AGS, Secretaría de Marina, libro 787, fs. 77-78v.

14. AGS, Secretaría de Marina, libro 787, fs. 125-128.

15. AGS, Secretaría de Marina, legajo 612, libro de Asientos, Relación de la tablonería de pino que se necesita proveer en el departamento del Ferrol en todo el año próximo de 1754 para 12 navíos de 68 cañones [...].

16. AGS, Secretaría de Marina, legajo 612, libro de Asientos. 
a la compañía comercial de Blanckenhagen o a comerciantes particulares, como es el caso de Herman Fromhold. El mismo mecanismo empleaban para conseguir maderas en otros puertos, como lo demuestra el ejemplo de Danzig/Gdansk, donde los mercaderes de la casa francesa de don Juan Mathy y el comerciante particular Antonio de Cuyper, con su hijo, recibían solicitudes para comprar maderas ${ }^{17}$.

Por otra parte es importante señalar la posición estratégica de los cónsules españoles, quienes representaban a la Corona en Ámsterdam y en ocasiones apoyaban el desarrollo de negocios y redes comerciales. Ese es el caso de Juan Manuel Uriondo, quien en varias cartas al Secretario de Hacienda, Miguel de Múzquiz, le informaba sobre las posibilidades de adquirir la tablazón y la arboladura en Stavanger, Danzig/ Gdansk y Riga. En 1770 intermedió en el trato con Herman Fromhold, quien se comprometió a comprar las arboladuras de pino en Riga, que escaseaban en el mercado, debido a la alta demanda por parte de las industrias navieras de Gran Bretaña y Francia. Las habilidades del cónsul permitieron conseguir dichos palos y además garantizar el beneficio para la Real Hacienda, debido a sus minuciosas observaciones sobre los valores de cambio de monedas en diferentes puertos de la Europa del Norte, señalando que:

Hay ocasiones en que el envío de Rixdalers ${ }^{18}$ a Riga produce ahorro; pero hoy conviene más él que se libre de allí [Ámsterdam] para esta plaza y aun ganará así el rey $1,25 \%$. Ya que 2,5\% cuestan al presente de más de su valor los rixdalers si se compran en partida. Su transporte y seguro va a $1,25 \%$ y el cambio de aquella plaza [Riga] para esta, no pasa de 2,5\% ahora. He advertido pues a Herman Fromhold [que] me libre en cuanto no haya novedad si la hubiese de modo, que de remitir rixdalers haya de resultar beneficio a la Real Hacienda ${ }^{19}$.

Al terminar este apartado que toca la cuestión de la legislación de transportes de madera, vale la pena tener en cuenta el periodo de realización del viaje entre el Báltico y España, el cual variaba dependiendo de las condiciones climatológicas, tipo de cargamento (menos y más pesado), estado físico del barco, y en tiempo de guerra, de los bloqueos navales. En caso de la Marina española, se mantenían contactos comerciales directos e indirectos de El Ferrol, Cádiz y Cartagena con

17. AGS, Secretaría de Marina, legajo 616, libro de Asientos, varios expedientes.

18. Rixdale es la palabra francesa para una moneda de plata antigua que se introdujo en los Países Bajos en el siglo XVI y en gran parte del norte de Europa. Este nombre viene directamente del Reichsthaler alemán, una gran moneda de plata de unos 27 gramos, hecha en 1550 por las autoridades monetarias del Sacro Imperio Romano, o tálero. Abreviada por la aféresis en daalder, expresión utilizada por los comerciantes de las Provincias Unidas durante sus transacciones comerciales y que duró incluso en las colonias americanas, esta moneda equivalía a la moneda de ocho reales españoles.

19. AGS, Secretaria y Superintendencia de Hacienda (avisos de la Marina), libro 55. 
puertos bálticos como Estocolmo, Wolgast, Stettin, Danzig, Königsberg, Memel, Riga, San Petersburgo ${ }^{20}$ y demás, donde las distancias variaban e influían en el tiempo de los derroteros. Sin embargo, se puede establecer un itinerario tentativo de los viajes en la ruta más frecuentada, es decir entre Riga y El Ferrol, con base en la navegación del navío holandés Rosenkrantz, cargado de madera y cáñamo, que realizó cabotaje en dicho recorrido entre el 4 de agosto y el 12 de septiembre de $1767^{21}$. Entonces, resulta que el viaje del Báltico a la Península Ibérica duraba alrededor de 6 semanas de ida.

\section{TRANSPORTES DE ASIENTOS AMERICANOS}

En esta parte del artículo se pretende demostrar las diferencias entre los asientos metropolitanos y los americanos. Como ejemplo se tomarán aquellos otorgados para extraer las maderas de los bosques de la Capitanía General de Cuba y de la provincia de Veracruz en el virreinato novohispano. Con ello, podremos observar las diferencias que surgieron en la organización logística y de transporte.

El caso más temprano que se presenta viene del asiento para construcción de navíos del rey por la Real Compañía de Comercio de La Habana. En diciembre de 1740 se firmó el contrato entre la Marina y dicha empresa para la elaboración de buques por 10 años. El presidente del consorcio, don Martín de Arostegui, al firmar el acuerdo asumió la responsabilidad de suministrar el astillero habanero no solo con la madera y piezas labradas, sino que también se comprometió a proveer «[...] fierro, clavazones, maestranzas y de más que se necesite para la entera construcción de cada bajel $[\ldots] »^{22}$. La mayoría de estos materiales y algunas maderas específicas no se pudo conseguir fácilmente en Cuba, por eso la compañía se vio obligada a comprarlos y traerlos en sus propios barcos desde España. Estas obligaciones

20. En el Archivo de Museo Naval de Madrid en el tomo I del ramo Derroteros (doc. 4 fs. 132-190) se encuentra un diario de navegación del teniente de fragata de la Real Armada, don Alonso de Torres Guerra quien participó en el viaje diplomático de El Ferrol a Kronstad, el puerto satélite de San Petersburgo. El viaje en el paquebote San Gil, que sufrió ciertos daños en sus aparejos y arboladura durante un temporal, duró 40 días (entre 2 de julio y 11 de agosto de 1778). Con ello se puede suponer que la navegación comercial pudo tardar más tiempo debido al hecho que los barcos de carga eran lentos.

21. AGS, Secretaría de Marina, Arsenales, legajo 340. Cuentas.

22. AGS, Secretaría de Marina, libro 786 exp. titulado: Por cuanto el infante Don Felipe, mi muy caro, y amado hijo, almirante general de todas mis fuerzas marítimas de España y las Indias, pasó a mis reales manos en 21 de diciembre del año próximo antecedente de 1740, un pliego y allanamiento que vos don Martín de Arostegui [...], le habíais presentado con fecha de 19 de noviembre antecedente, en que en nombre de la Compañía establecida en la misma isla con mi real aprobación [...], os obligáis a la construcción de navíos en el astillero de La Habana, y a la provisión de víveres para mis bajeles [...]. 
aparecen claramente señaladas en el capítulo $\mathrm{V}$ del contrato, donde se indicaba que la arboladura «fuese traída de los departamentos de España». Sin embargo, el capítulo VII introducía una alternativa, que aprovechaba la compañía en caso de no poder encontrar la arboladura en la metrópoli, pudiendo comprar «árboles que producen los montes de Coatzacoalcos, u otros, pagando por los necesarios para la arboladura de un navío de 70 cañones, 4.500 pesos fuertes; 4.000 pesos por los de la de uno de 60 cañones; 3.000 por los de uno de 50 y 40 cañones; $y 1.500$ por los de uno de 30 cañones cuyo valor debiese de descontarse asimismo del capital de cada navío» ${ }^{23}$. Todavía en el capítulo VIII del asiento se otorgaba a la compañía de La Habana la posibilidad de conseguir dichos árboles en «los parajes, sin excepción de países extranjeros, donde la tuviere más cuenta, y conducirlos a La Habana con navíos propios o extraños $[\ldots]{ }^{24}$, siempre cuidando las medidas, gruesos $\mathrm{y}$, por supuesto, la calidad de madera.

Las posibilidades que otorgó la Corona a la Compañía para tener acceso constante a las arboladuras de diferentes lugares del mundo atlántico demuestran la importancia de mantener el flujo continuo de los suministros navales para asegurar la estabilidad de la construcción de buques del rey durante un tiempo prolongado y con un presupuesto flexible a las circunstancias. De hecho, esta práctica de otorgar cierta autonomía para buscar materias primas para el departamento naval de La Habana se extendió a otras décadas del siglo XVIII, lo que ilustran los ejemplos de contratación de don Rasmus Jande Smit, el capitán de la urca holandesa nombrada el Federico Henrik, quien en 1766 ejecutó el viaje de El Ferrol a La Habana, con palos de arboladura ${ }^{25}$, y de don Thomas Teisen, capitán de otra urca neerlandesa Juana Erica, que en 1785 arribó al puerto cubano con piezas de madera y otros efectos $^{26}$. Sin embargo, la mayor parte de los suministros forestales para el astillero de La Habana provenía de los montes de la parte central de Cuba, es decir, de las provincias de Sancti Spíritus, Camagüey y Manzanillo. Las reservas propias de bosque en la isla brindaban al departamento una ventaja para construir buques más baratos y en menos tiempo, debido a la poca distancia entre los ranchos de tala y el puerto habanero.

Otra diferencia de los transportes americanos con respecto a los peninsulares, que prácticamente quedaron en fletes privados, es que los de las Indias, por lo

23. AGS, Secretaría de Marina, libro 786 exp. titulado: Por cuanto el infante Don Felipe..., f. 1v.

24. AGS, Secretaría de Marina, libro 786 exp. titulado: Por cuanto el infante Don Felipe..., f. 1v.

25. AGS, Tribunal Mayor de Cuentas de la Marina, libro 4201, f. 8v. Don Joseph Antonio de Ponte, tesorero de Marina del departamento del Ferrol. Su cuenta desde $1^{\circ}$ de enero de 1766 hasta fin de noviembre de 1768.

26. Archivo Nacional de la República de Cuba (en adelante ANRC), Intendencia General de Hacienda, legajo 904, orden 20, fs. 1-4. Registro y flete de la urca holandesa Juana Erica. 
general, se asignaban a los barcos de la propia Marina Real. Por ejemplo, en el caso del virreinato novohispano, dicha regla funcionaba desde los primeros contratos de la década de 1760, que se asignaron a los asentistas criollos, donde éstos únicamente estaban obligados a realizar cortes de madera, a labrar piezas, si así señalaba el contrato y a entregar troncos, palos y tozas en uno de los puntos de acopio, que se encontraban en las desembocaduras de los ríos de Coatzacoalcos y Papaloapan, y en la laguna de Términos. Después, dichas maderas se cargaban en las embarcaciones del rey, raramente en las de los particulares, y se enviaban a los puertos de Campeche y Veracruz. Una demonstración de ello, es el contrato del bachiller don Antonio Basilio Berdeja, apoderado general del capitán don Andrés Berdeja, quien en febrero de 1766 firmó un asiento de cinco años para surtir el real almacén del puerto veracruzano con piezas labradas de cedro y caoba extraídas de los montes de Tlacotalpan, donde su único compromiso era llevar la madera a la ría de Papaloapan y depositarla bajo la vigilancia de los oficiales reales. Según el asiento, el traslado desde allí a Veracruz quedaba a cargo de la Real Hacienda, que debía garantizar el flete en buques del rey ${ }^{27}$.

Igual situación encontramos en un corte de madera realizado por la Corona en los montes de Oaxaca, Santa María de Chimalapa, donde se talaron 510 pinos para arboladuras, que fueron fletados hasta la desembocadura de Coatzacoalcos, el punto de acopio del cual las piezas fueron transportadas en barcos del rey directamente a La Habana y a Veracruz; desde este último puerto se realizó su redistribución a los departamentos navales de España. Sin embargo, la recomendación del empleo de buques reales no fue un suceso oportuno, ya que a menudo faltaban los barcos de carga, lo que demuestra el ejemplo de junio de 1769 cuando del total de las arboladuras enviadas desde Chimalapa, se transportaron apenas 54 piezas, en dos paquebotes de Su Majestad: el San Lorenzo, que cargó 27 piezas en ocho días; y el San Francisco de Paula, que cargó 37 palos en diez días. La permanente falta de transportes causaba la pérdida de madera, que estaba expuesta a las fuerza de la naturaleza ${ }^{28}$.

Un método alternativo para transportar maderas a la metrópoli era embarcarlas en los navíos sueltos o en los de la flota de Nueva España. Ejemplo de ello, es el registro del navío La Pastora, propiedad de don Alonso Varcárcel, el cual a su retorno desde Veracruz a Cádiz en la flota del Señor Tilly del año de 1773, transportó varias partidas de madera a un flete regular en los términos siguientes:

- Don Pedro Antonio de Cossío cargó por su cuenta para entregar a don Jacinto de Barrios 172 tablones de cedro y 11 tosas que mediaban 207 codos cúbicos, a 24 reales de plata fuerte de flete cada codo desde Veracruz a Cádiz.

27. Archivo General de la Nación de México (en adelante AGNM), Industria y Comercio, vol. 10, exp. 2, fs. 50-73. Asientos de madera novohispana.

28. AGNM, Industria y Comercio, vol. 10, exp. 1, fs. 1-49. Asientos de madera novohispana. 
- En el mismo navío y ocasión cargó don Juan de Villoa, Maestro de esta flota, por cuenta y riesgo de don Miguel de Soto 94 tablones de cedro y 32 palos con 375 codos cúbicos, a 32 reales de plata fuerte de flete cada codo.

- En la misma ocasión y navío cargó el mismo Villoa, por cuenta del mismo Soto, 21 tablones con $252 / 3$ codos cúbicos a 24 reales de plata fuerte cada codo ${ }^{29}$.

Mencionado en dos ocasiones, don Miguel Soto fue uno de los asentistas de madera para los departamentos navales de El Ferrol, La Carraca y Cartagena, lo que demuestra que dichos contratistas buscaban cualquier oportunidad para realizar sus contratos. Por otro lado, los documentos históricos demuestran que esta práctica de embarque de cargamentos madereros en los barcos de particulares fue común, sobre todo en momentos en los que la Marina negaba la prestación de sus urcas. Sin embargo, este proceder tampoco fue regular debido a que las flotas novohispanas en el siglo XVIII circulaban irregularmente y con mucho atraso, por eso la Secretaría de Marina, al ver este constante problema de transporte de maderas entre las costas novohispanas y los departamentos navales, intentó priorizar dicho transporte, poniendo obligaciones a los barcos del rey y a las embarcaciones de comerciantes particulares. Ello se refleja claramente en una copia del orden real de 1784 titulada Advertencias para la empresa del corte de maderas de construcción en costas de Nueva España y su remisión a los departamentos de Marina, donde se aclaraba esta situación en el capítulo III, indicando:

La conducción [de maderas] a los departamentos de España o al de La Habana, según convenga, será de cuenta de S.M. bien sea en embarcaciones de su Real Armada o particulares; y en este caso el Señor Virrey arreglará el flete de cada codo cubico que conduzca con las ventajas que pueda, atendiendo las circunstancias que median, pues la urgencia de regreso a España sin cargar, como puede suceder, con algunos navíos del comercio, podrá abaratar el precio para lograr alguna utilidad, que no tendrían si vienense sin $\operatorname{carga}^{30}$.

Cabe decir que la década de 1780 fue de bonanza para el negocio maderero de los criollos novohispanos. En especial de los veracruzanos, quienes entre $1784 \mathrm{y}$ 1789 recibieron varios asientos para extraer maderas duras y de cedro con el fin de suministrar los departamentos de la Marina. Fue la consecuencia de la orden del secretario, don Antonio Valdés, quien en julio de 1783 dio su visto bueno para contratar la extracción de maderas novohispanas. Medio año después, se otorgaron los primeros asientos para José Jiménez (capitán de milicias de Tuxpan), Esteban

29. AGS, Secretaría de Marina (SMA), Arsenales, legajo 355. Cuentas.

30. AGNM, Reales Órdenes, exp. 147, f.52v. Advertencias para la empresa del corte de maderas de construcción en costas de Nueva España y su remisión a los departamentos de Marina. 
Bejarano (vecino de Veracruz), Pedro Moscoso (vecino de Acayucan), Ramón Carvallo (vecino de Tlacotalpan) y Francisco Sánchez de Burgos (subdelegado de la Antigua), quienes se obligaron a entregar más de 30.000 codos cúbicos de piezas de «todas clases de madera desde quillas hasta cepos de anclas con arreglo al plan formado por el delineador de construcción, don Luis del Toral, con arreglos a sus dimensiones señaladas y en los reglamentos que se les entregaron» ${ }^{31}$.

Ciertamente, no hay mucha información sobre el transporte de dichas piezas. Aparecen menciones sueltas como la de una partida, que salió de Veracruz el 8 de agosto de 1787 transportada por tres buques del rey, la fragata Santa Balbina (213 piezas labradas de madera), la urca Santa Rita (168 piezas) y el paquebote San Carlos (54 piezas), en la que el cargamento en su mayoría era de madera de cedro y constaba de 3.481 y 239/576 codos cúbicos de 576 partes, de un valor de 15.000 pesos y 5 reales ${ }^{32}$.

Ya se ha mencionado que el transporte de maderas novohispanas fue un problema continuo para los oficiales de la Marina y los virreyes, porque constantemente faltaban buques para fletarla, lo que señaló en su informe del 11 de julio de 1787 el intendente de Veracruz, Pedro Corbalán, quejándose de que «la madera cortada y existente en esa plaza [Veracruz], que no se hubiese enviado a los departamentos de la Marina ni tampoco se hubiesen vendido a particulares no se pudiese utilizar debido a su mal estado», por lo cual solicitó la suspensión de acopios de piezas según los contratos que se firmaron con los asentistas veracruzanos. Dicha petición estaba justificada por el deterioro que padecían las maderas acopiadas en las playas de Veracruz, ya que estaban mucho tiempo expuestas al sol, al aire y al agua ${ }^{33}$. Esta situación fue anteriormente manifestada por el virrey de Gálvez, quien en su carta de 1785 informaba al rey que varias piezas no estaban bien labradas, teniendo dimensiones diferentes a las solicitas a los asentistas novohispanos, pero sobre todo subrayaba la falta de embarcaciones para transportar las maderas a los arsenales reales (Andrade Muñoz, 2006: 95-96).

El mismo problema mencionaron en su informe los oficiales reales de Veracruz, Bernardo Troncoso, Francisco Antonio de Agudo, José María Lasos y Juan Matías de Alcanza, avisando al virrey Marques de Sonora sobre la escasez de fletes para cargar las maderas. En el documento, señalaban que en varias ocasiones solicitaron el envío de cuatro urcas del rey procedentes de La Habana, con el fin de cargarlas en ese puerto y enviarlas a Cuba y a España. Cuando finalmente lograron convencer al intendente de la Marina del apostadero cubano, este únicamente les envió

31. AGNM, Industria y Comercio, vol. 31, exp. 5, f. 104v. Asientos de madera novohispana.

32. AGNM, Industria y Comercio, vol. 10, exp. 16, f. 371. Asientos de madera novohispana.

33. AGNM, Correspondencia de Diversas Autoridades, vol. 41, exp. 67, fs. 316 y $316 \mathrm{v}$. Informe de transporte de maderas. 
dos barcos en los cuales pudieron cargar la mitad de la madera de la antecedente graduación, quedando la otra parte expuesta a sufrir «el quebranto y el perjuicio». Los funcionarios veracruzanos tomaron la iniciativa y también lograron embarcar alguna porción de cedro y caoba por cuenta de Real Hacienda en las embarcaciones de comercio que se dirigían a Cádiz y Málaga ${ }^{34}$.

La escasez de buques en el departamento de La Habana para el transporte de maderas viene confirmada por otro informe del 11 de julio de 1783, elaborado por el recién llegado comandante del departamento, Francisco de Borja, Marqués de Camachos, en el que el oficial enumeró 15 embarcaciones de carga, de las cuales cinco estaban en carena en tierra, cuatro tenían maderas con $2 / 3$ del servicio cumplido, y las demás estaban a medio uso de su vida ${ }^{35}$. Desafortunadamente, el documento no menciona las razones por las que más de la mitad de la flota transportista de La Habana no estaba en condiciones de servicio. Sin embargo, tomando en cuenta el periodo de elaboración del informe, se puede sospechar que esta situación se debió a la guerra de la Independencia de las Trece Colonias (1775-1783), el periodo en el que se priorizó el mantenimiento de las tropas y la operatividad de los buques de guerra y no la de los de transporte. Asimismo, fueron constantes las quejas de las autoridades novohispanas ante la falta de fletes para conducir maderas, que demuestran que el departamento de La Habana no pudo resolver dicho problema, principal obstáculo en el constante transporte de pertrechos navales desde tiempo atrás.

¿Por qué la industria maderera en las Indias aparentemente brindaba más problemas que beneficios? La respuesta no es fácil pero las pistas sobre el manejo del dinero real en Hispanoamérica indican que la gente involucrada en la extracción de maderas para suministro de los arsenales reales, buscaba su propio interés, sacando el mayor provecho del dinero estatal que recibía. Esta tesis puede venir fortalecida por el ejemplo de la construcción de barcos en Coatzacoalcos, donde después de varios intentos se construyó un único navío de 60 cañones bautizado San José, alias Nueva España, que costó al real erario 431.784 pesos, dos reales y diez granos y su elaboración duró más de 4 años. Los oficiales virreinales que vigilaban la obra, en varias cartas que intercambiaron con el Secretario de Marina, José Patiño, mencionaban que los comerciantes criollos aprovechaban su monopolio de herramientas, mano de obra y animales necesarios para subir los precios por sus servicios, lo que constantemente aumentaba el presupuesto. Además, en sus comunicaciones, señalaban que durante la obra se realizaron múltiples desvíos de recursos por fraude y corrupción (Andrade Muñoz, 2006: 63).

34. AGNM, Real Hacienda, vol. 44, fs. 169-171 y 238. Cuentas.

35. AGS, Secretaría de Marina, libro 371, exp. titulado: Se le previene que abrevie con su celo la construcción de dos navíos de 90 cañones mandados fabricar en aquel puerto con el donativo del cabildo de Nueva España y el del Conde de Regla. 
Lo contrario sucedía en el caso de los suministros de maderas peninsulares y europeas, en los que cada nuevo asiento que firmaba la Corona beneficiaba a la Real Hacienda, debido a que los asentistas ofrecían buenos descuentos y servicios adicionales para ganar el contrato y así situarse bien en el negocio de materias primas forestales que, por otro lado, generaba buenas ganancias. Esta realidad se observa claramente a lo largo de las negociaciones que estableció la Corona con las casas comerciales de Gil de Meester, Soto, Gahn y otras.

\section{EJEMPLOS DE GASTOS EN FLETES Y TRANSPORTES PROVENIENTES DEL BÁLTICO SUR}

Varias son las razones que explican por qué se determinó elegir ciertas rutas marítimas para llevar a cabo el suministro de maderas a los departamentos navales de España. Una de ellas es el informe de cuentas realizado por Joseph Antonio de Ponte, tesorero de Marina del departamento de El Ferrol para el periodo que va del 1 de enero de 1766 al 30 de noviembre de 1768. Entre los pagos por el flete se pueden dimensionar varios espacios marítimos: el Atlántico peninsular, el Mediterráneo, el Cantábrico, el Báltico y en menor medida el Caribe. Al analizar los precios por el flete, resulta que el transporte más costoso era precisamente ese último espacio marítimo, ya que por el viaje entre El Ferrol y La Habana al capitán Rasmus Jande Smit, de la urca Federico Henrik, que transportaba palos de arboladura y otros efectos de la Real Hacienda, se le pagó 96.617 reales de vellón y 22 mrs. El precio era muy elevado, comparándolo con el transporte de perchas y tablones de pino que realizó en julio de 1766 el mismo capitán en la ruta entre El Ferrol y Guarnizo, en el que por su servicio cobró 15.811 reales de vellón y 26 mrs. Comparando el precio del transporte de La Habana con el de Riga, un destino estratégico para el sistema de suministros de arboladura, tablazón y cáñamo, resulta mucho más barato el segundo, cotejándose en 37.191 reales de vellón y 14 mrs, precio que pagó la Real Hacienda en noviembre de 1766 al capitán Hermanus Kniebel de la urca La Susana por el flete de partida de cáñamo ${ }^{36}$.

Por otra parte, es probable que la Real Hacienda, que pagaba los fletes de los transportistas tanto nacionales como extranjeros, intentara manejar tarifas fijas a los puertos frecuentados por las embarcaciones que fueron empleadas en el traslado de los cargamentos madereros y de otras materias primas. La confirmación de esta regla son diversos fletes de Danzig/Gdansk, la ciudad portuaria de Polonia más importante, realizados en 1768, cuando el 30 de julio a los capitanes Edman

36. AGS, Tribunal Mayor de Cuentas de la Marina, libro 4201. Don Joseph Antonio de Ponte, tesorero de Marina del departamento del Ferrol. Su cuenta desde $1^{\circ}$ de enero de 1766 hasta fin de noviembre de 1768. 
RAFAEL REICHERT

EL TRANSPORTE DE MADERAS PARA LOS DEPARTAMENTOS NAVALES ESPAÑOLES

EN LA SEGUNDA MITAD DEL SIGLO XVIII

Tabla 2. Precios por los fletes de materias primas forestales transportadas por los barcos extranjeros

\begin{tabular}{|l|l|l|l|}
\hline $\begin{array}{l}\text { El Ferrol - } \\
\text { Guarnizo }\end{array}$ & Riga - El Ferrol & Danzig - El Ferrol & $\begin{array}{l}\text { El Ferrol - } \\
\text { La Habana }\end{array}$ \\
\hline $\begin{array}{l}\text { 15.811 reales } \\
\text { de vellón y 26 } \\
\text { maravedís }\end{array}$ & $\begin{array}{l}37.191 \text { reales } \\
\text { de vellón y 14 } \\
\text { maravedís }\end{array}$ & $\begin{array}{l}34.360 \text { reales de } \\
\text { vellón }\end{array}$ & $\begin{array}{l}\text { 96.617 reales } \\
\text { de vellón y 22 } \\
\text { maravedís }\end{array}$ \\
\hline
\end{tabular}

Fuente: AGS, Tribunal Mayor de Cuentas de la Marina, libro 4201. Don Joseph Antonio de Ponte, tesorero de Marina del departamento del Ferrol. Su cuenta desde $1^{\circ}$ de enero de 1766 hasta fin de noviembre de 1768 .

Friederiksen y Gregorio Wonder se les pagó 68.720 reales de vellón por el flete de tablazón de pino; el 21 de septiembre se pagó a Martin Zaddach, capitán de la urca La Astrea, 34.360 reales de vellón por el transporte de partida de tablones; y el 26 de noviembre cuando el capitán Emanuel Martens de la urca El Moreciente recibió 34.360 reales de vellón por el flete de partida de tablazón de pino que se compró por cuenta de la Real Hacienda. Se puede observar que de los cuatro transportes señalados se pagó a los capitanes la cuota igualada por su servicio, es decir 34.360 reales de vellón, lo que puede sugerir que la Real Hacienda y los asentistas ofrecían un precio fijo por los transportes de maderas ${ }^{37}$. En el caso del puerto de Danzig/ Gdansk, se ha podido encontrar una ordenanza del Ayuntamiento de la ciudad sobre el almacenamiento y cargamento de diferentes tipos de maderas de junio de 1751. En el capítulo XI se señala cuánto dinero debiera pagarse a los peones que realizaban la obra de acomodar tablazón en una embarcación. Así por una medida de 60 tablones:

- de 4 pulgadas de grosor y más de 6 brazas de largo se pagaba 14 florines.

- de 4 pulgadas de grosor y de 6 brazas de largo se pagaba 11 florines.

- de 4 pulgadas de grosor y de 5 brazas de largo se pagaba 9 florines.

- de 3 pulgadas de grosor y más de 5 brazas de largo se pagaba 9 florines.

- de 3 pulgadas de grosor y 5 brazas de largo se pagaba 8 florines.

- de 3 pulgadas de grosor y 4 brazas de largo.

- así como de 3 pulgadas y media se pagaba 6 florines y de 2 pulgadas se pagaba 5 florines $^{38}$.

37. AGS, Tribunal Mayor de Cuentas de la Marina, libro 4201. Don Joseph Antonio de Ponte, tesorero de Marina del departamento del Ferrol. Su cuenta desde $1^{\circ}$ de enero de 1766 hasta fin de noviembre de 1768.

38. Archivo Estatal de Gdansk (en adelante AEG), Polonia. Ramo: Edykty, legajo 300.93_55g, foja 291. Klapper-Wiesen Ordnung E. E. Rahts der Stadt Dantzig wornach alle 
Desafortunadamente, hasta la fecha no se dispone de un trabajo únicamente centrado en la cuestión de fletes y transportes de materias primas forestales, ni siquiera para otros productos hay más información. Sin embargo, para precios por cargamento en Danzig/Gdansk se pueden encontrar algunas pistas en las investigaciones de historiadores polacos como Antoni Mączak (1972) y Maria Bogucka (1962 y 1968), quienes en sus aportaciones realizaron análisis de precios de cereales y de su flete en el puerto gdanskiano, donde ambos establecen la tesis de que el precio variaba dependiendo de la abundancia o escasez de los trigos en la ciudad. Con ello observaron que en los años de elevado precio por dicho producto agrícola el flete representaba un $23 \%$ del valor total de un last ${ }^{39}$ de cereal y con el precio bajo disminuía a $16 \%$ por unidad. Los trabajos de Mączak y Bogucka estudiaron únicamente dicha dependencia para el siglo XVII. En cambio, para el siglo XVIII no se cuenta con trabajos que comparen el precio de flete con el precio de las materias primas.

Por su parte, en la documentación del fondo de «Asientos» del Archivo General de Simancas se pueden rastrear pistas que tocan el tema sobre los gastos que los comerciantes del Báltico sur pagaban por flete, transporte y seguro. Un buen ejemplo de ello es una carta del conde Bene, el cónsul de España en Gdansk/Danzig, en la que adjunta una factura por la compra de arboladuras, palos chicos, pre-cintas de roble, bordajes de roble y tablones de roble, enviadas en el navío gdanskino Augusto III, el Rey de Polonia al mando del capitán Valentín Flemming, en la que el valor del cargamento era de 3.211 pesos fuertes. En la factura también aparece el costo por el seguro de Danzig a Cádiz del $6 \%$ del valor de la madera (192 pesos) y del flete de Danzig a Cádiz (1.200 pesos). Este último dato da idea de que el valor de flete marítimo era bastante caro - en este caso fue del $37 \%$ del valor completo del cargamento - y seguramente dependía de la situación política (periodo de paz o de guerra) y de la logística (escasez y abundancia de barcos transportistas) ${ }^{40}$. En otro caso más tardío, de octubre de 1761, se menciona que a un navío holandés Santa Cornelia Hermina capitaneado por Claas Paulien, el cual cargó 4.403 tablones polacos por valor de 80.825 reales de vellón desde Danzig a El Ferrol, además del 5 \% del seguro (4.401 reales de vellón), se le cobró una cantidad enorme por el flete, concretamente, 76.700 reales de vellón (94 \% del valor de madera) y una comisión en Ámsterdam del 2 \% (1.697 reales de vellón $)^{41}$. Obviamente, este precio por el

Bediente der beyden Klapper-Wiesen und Männiglich daselbst sich zu verhalten haben. Publiciret im Monat Junio 1751. Dantzig.

39. Unidad para volumen empleada por los comerciantes de la región del Báltico y el Mar del Norte que equivale a unos $1900 \mathrm{~kg}$ por unidad.

40. AGS, Secretaría de Marina, libro 612, exp. titulado: Esto se ha de tener presente por el asiento de arboladura, luego que llegue Rooth.

41. AGS, Secretaría de Marina, libro 616, exp. titulado: Don Gerónimo Retortillo, asentista de la provisión de arboladura del Norte. 
transporte fue efecto de la Guerra de los Siete Años (1756-1763), el conflicto bélico que azotó Europa, durante el cual Gran Bretaña mantuvo bloqueos y puso mayor vigilancia sobre los transportes bálticos a Francia, y a partir de enero de 1762 a España, que se involucró en la contienda tras la firma del Pacto de Familia.

Vale la pena añadir una propuesta sobre la compra de maderas de roble proveniente de binterland del río Oder, que realizó Felipe Chone durante su visita en el puerto de Stettin en agosto de 1775. En su informe realizó algunas simulaciones de gastos de compra y transporte de piezas labradas, donde, por ejemplo, al comprar 3.750 pies cúbicos de tablas de diferentes dimensiones con un valor de 1.249 florines de Holanda, debía añadir también los gastos en seguros (3\%), comisión de seguros $(0.5 \%)$, avería (10\%) y el flete de Stettin a España, que ascendían todos ellos a una cantidad de 1.500 florines holandeses (120\% del valor de la madera!). Como se puede observar, ya el costo de transporte es mayor al valor de la madera, lo que puede sugerir que a lo largo de la segunda mitad del siglo XVIII la demanda de fletes fue tan alta que los comerciantes pudieron elevar significativamente el precio por el transporte, lo que les permitía recuperar el «precio de oferta» por la propia madera. Lo interesante en el informe de Felipe Chone es la mención de los gastos por llevar y entregar la carga en el bordo de barcos anclados en el puerto de Stettin, que fue de 1 y 1/4 de gruesos por cada pie cubico, el $0.5 \%$ por derechos del Sund y su comisión del $3 \%$. El total del costo por los servicios de peones ascendía a 3.192 florines y el total del envío completo a 4.441 florines holandeses, que equivalían a 21.999 reales de vellón ${ }^{42}$.

Finalmente, al observar los gastos por transporte en los espacios marítimos donde la corona española mantenía la navegación, es muy notable el costo elevado que gastaba la Real Hacienda por los transportes desde los departamentos peninsulares a La Habana, claro que en este caso la distancia era el triple con respecto, por ejemplo, al caso de la ruta entre El Ferrol y Danzig; sin embargo, tomando en cuenta que no era necesario pagar ni por el depósito de maderas a bordo de la embarcación, ni por pasar el Sund donde se cobraba el peaje, resulta algo sospechoso ver que el precio casi se triplicaba (37.191 reales de vellón y 14 maravedís frente a 96.617 reales de vellón y 22 maravedís); además del hecho de que a su regreso las embarcaciones podían cargar alguna de las mercancía cubanas (tabaco, azúcar o aguardiente) en La Habana para venderla en España. Esta tendencia de precios elevados para los transportes hacia o desde las Indias se puede explicar únicamente por no contar con suficiente cantidad de embarcaciones del rey capaces de cruzar el Atlántico, por lo que los comerciantes particulares ofrecían los precios elevados por su servicio de

42. AGS, Secretaría de Marina, libro 624, exp. titulado: Don Felipe Chone. Acompaña la nota de las apuntadas a cerca de madera de roble [que] reconoció en el puerto de Stettin. 
transporte y flete, que la Marina tuvo que aceptar para mantener el suministro de materias primas del departamento de La Habana.

GRÁfico 1. Esquema de estructura de transportes de materias primas forestales entre diferentes espacios marítimos y los departamentos navales de la península y La Habana

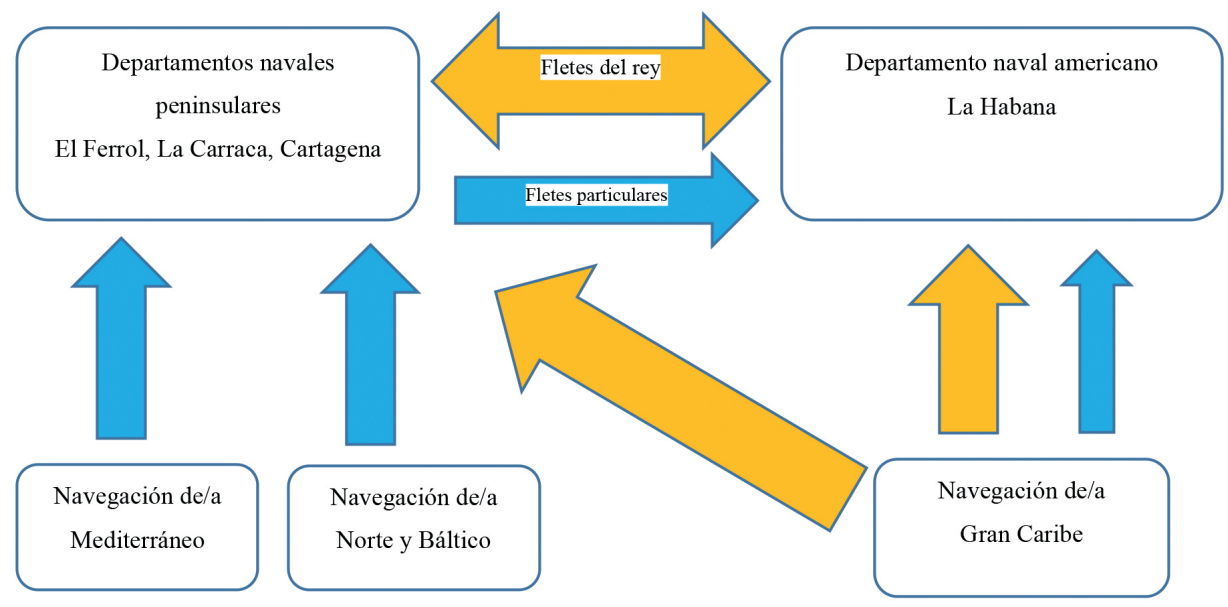

Fuente: Elaboración propia.

\section{EL PROBLEMA DE LA MEDIDA, TIPO, CALIDAD Y CANTIDAD DE MADERAS CONTRATADAS}

Un problema que a menudo enfrentaban las autoridades de los arsenales reales y puertos españoles fue el «aprovechamiento» de asientos de madera del Norte, por los barcos provenientes del Báltico para vender su madera fuera del registro acordado en la contrata entre la Corona y asentista. Este fenómeno no fue nada nuevo y fue común desde los primeros contratos firmados todavía en la década de 1740. Por esta razón, los oficiales de los departamentos navales fueron obligados a examinar cada cargamento. Por ejemplo, en enero de 1752 arribó a Cartagena una urca holandesa llamada Jacoba Gertrudis, que condujo por cuenta del asiento de los Gil de Meester maderas del Norte, que, según la solicitud, debían ser palos mayores y trinquetes para los navíos de 70 cañones. Sin embargo, tras la revisión del cargamento por el capitán de maestranza don Martín de Esparza y el maestre mayor de arboladura, don Eduardo Bryant, resultó que la urca trajo arboladura de muy poca utilidad, debido a sus malas dimensiones, y mucha tablazón que el 
departamento no había solicitado. El intendente del departamento naval de Cartagena, don Francisco Barrero Peláez, en su carta al ministro de la Marina solicitaba que se diera «la orden que [la madera] fuese más de su agrado y para que se remita la correspondiente [del asiento] para hacerse a su tiempo la que debe servir a los [navíos] de aquel porte [de 70 cañones] que se han de construir en este puerto». ${ }^{43}$

Igual ocurrió en agosto del mismo año, cuando el capitán Jacobo Meris de la urca holandesa San Pedro, al cumplir con el asiento de los Gil de Meester, entregó en La Carraca pino del Norte que fue recibido por los oficiales del arsenal. Sin embargo, la Contaduría General de la Marina del departamento de Cádiz señaló que «adviértase a que no siendo lo contratado el cargamento de esta naturaleza sin árboles que debió proveer el capitán Jacobo Meris para que estas maderas sirvieran de estiba hubiese de suministrar por cuanto expresamente señalada en su citado asiento, las que debían venir sirviendo a este efecto» ${ }^{44}$.

Aparentemente, el problema de las entregas de maderas no solicitadas mediante los asientos continuó en el tiempo y los oficiales de los departamentos navales mantuvieron sus quejas, como demuestra el caso de la fragata sueca La Diligencia, que en febrero de 1767 arribó a Cádiz con tablazón de encina, la cual no tenía buenas características para ser utilizada en la construcción de buques, sin embargo, el intendente la recibió debido a la falta de maderas para otras obras de carpintería, para la que se podía utilizar cualquier tipo de maderas de baja calidad, sin especificación y elaboración previa ${ }^{45}$.

Otro fenómeno interesante es el aumento de precios por parte de los transportistas en el momento de la entrega de las maderas en los departamentos españoles, con el argumento del tipo de cambio de monedas entre la Europa del Norte y España; el aumento de tarifa de flete; los crecientes peajes y otras explicaciones que aparentemente tenían como fin, el beneficio de no pagar aranceles en el puerto de destino y con ello sacar un «extra» por su propia cuenta fuera de los asientos establecidos. Un caso así es el de Swen Hagman, el capitán del navío sueco La Fortuna, quien arribó el 19 de septiembre de 1767 a Cartagena con madera de pino para la construcción, fierro, acero, brea y cáñamo. El escandinavo intentó recibir más dinero de lo que aseguraba su contrato, sin embargo, los oficiales de la Marina no se dejaron engañar. Después de la minuciosa revisión del cargamento, le permitieron únicamente no pagar los aranceles por maderas, cobrando los impuestos por los demás bienes ${ }^{46}$.

Ante estos abusos, las autoridades de la Armada establecieron escrupulosos exámenes de la madera, por parte de los carpinteros y delineadores, para calificarla

43. AGS, Secretaría de Marina, Arsenales, legajo 612. Informe.

44. AGS, Secretaría de Marina, Arsenales, legajo 612. Informe.

45. AGS, Secretaría de Marina, Arsenales, legajo 339. Informe.

46. AGS, Secretaría de Marina, Arsenales, legajo 339. Informe. 
según sus condiciones como beneficiosa para el arsenal y construcción naval o no. En caso de no ser apta para la Marina, se recomendaba su venta libre en el mercado, siempre y cuando se pagaran derechos, que, por ejemplo, en Cádiz eran del $15 \%$ del valor de maderas ${ }^{47}$. Además, las autoridades de puertos y departamentos navales requerían de los barcos que traían pertrechos para la Armada Real que demostraran que realmente dicho cargamento formaba parte del asiento, lo que se comprueba a través de una ordenanza del 20 de mayo de 1783 enviada por el secretario de la Marina a los oficiales gaditanos, cuando intentaron cobrar derechos a José Antonio Almera «por lonas, lienzos, vitres, brea y maderas que de Danzig, Riga y San Petersburgo remitió don Pedro Normande, encargado del negocio español en Rusia, para el servicio de la Marina de Guerra y que todos los derechos iban por cuenta de la Real Hacienda $»^{48}$.

\section{REFLEXIONES FINALES}

En el presente artículo se ha pretendido presentar el sistema de fletes y transportes que se empleó para mantener el suministro de pertrechos navales para la Marina española en la segunda mitad del siglo XVIII. En la aportación se han presentado diferentes métodos de transporte marítimo del rey y de los particulares: el transporte marítimo en navíos del rey fue utilizado para los cargamentos americanos, mientras que el sistema de comerciantes privados se empleó para organizar transportes de madera desde el Báltico. En el caso de la empresa real, la Corona tuvo permanentemente que enfrentarse a la escasez de embarcaciones para garantizar la circulación constante entre los lugares de acopio de maderas y los departamentos navales. Esta dificultad influyó en la perdida de maderas y piezas labradas, que quedaban expuestas a las condiciones climatológicas mientras se organizaba el transporte. Por su parte, al dejar el transporte y el flete en manos de los asentistas, como en el caso de los Gil de Meester, los suministros llegaban a tiempo y en abundancia, pero no siempre según los capítulos acordados en contrato, donde tanto asentistas como capitanes de barcos cargaban piezas que no cumplían con las dimensiones, cantidades y calidades señaladas en los asientos.

47. Archivo Histórico Provincial de Cádiz (en adelante AHPC), Escribanía de Marina, exp. 1212: «La madera que se introduzca para uso de navíos de la Real Armada o particulares está libre de derechos, pero la dedicada a la negociación debe pagar el $15 \%$ \%. 14 de noviembre de 1783; exp. 1660: «Que no se proceda al cobro de derechos al navío Rey Branderburgo de una cantidad de madera si acredita haberla invertido en buques de la Real Armada [...]». 27 de marzo de 1792; y exp. 1875: «Que la casa de Ghan y Compañía pague los derechos al contado de las maderas que no acredite haber invertido en la construcción naval». 20 de noviembre de 1792.

48. AHPC, Escribanía de Marina, exp. 1099. 
Por otra parte, una cuestión importante eran los precios de fletes y transportes que aparentemente variaban según las distancias y acceso a las embarcaciones: el rumbo más caro era el que se establecía entre la metrópoli y La Habana, donde los precios se duplicaban o triplicaban en comparación con los que se pagaba desde los mares europeos. Quizás por esta razón, la Marina buscó surtir el departamento cubano con las especies americanas provenientes de la Nueva España, la Florida y la Luisiana. Por su parte, los precios por fletes europeos eran más baratos, pero al analizar los contratos de Riga, Gdansk y Stettin, se demuestra que la mayor parte del dinero invertido en la compra de maderas bálticas, se destinaba al pago del transporte, peajes, jornadas de cargadores portuarios y seguros.

Otro aspecto importante que se puede observar a lo largo del texto, son las rutas de navegación que los departamentos navales de El Ferrol, Cádiz-La Carraca y Cartagena establecieron por los mares europeos, el Atlántico Norte y el Gran Caribe. La red que se creó mediante los transportes de suministros madereros y otros bienes demuestra que el Estado borbónico en la segunda mitad del siglo XVIII formó parte del desarrollo del mercado global de materias primas, donde, a pesar de la dominación de los británicos y holandeses, pudo mantenerse firme en un negocio que le garantizaba los pertrechos necesarios para seguir con la construcción naval y desarrollar su Marina Real, la cual en aquel entonces intentaba enfrentarse a la hegemonía de la Royal Navy.

\section{BIBLIOGRAFÍA}

Andrade Muñoz, G. L. (2006). Un mar de intereses. La producción de pertrechos navales en Nueva España, siglo XVIII. México: Instituto Mora.

Aragón Ruano, Á. (2011). La historiografía forestal sobre época moderna en el panorama internacional, español y vasco: una revisión bibliográfica. Vasconia, 37, 117-140.

Aragón Ruano, Á. (2017). Mar de árboles, vorágine de jurisdicciones. La complicada relación entre la Real Armada española y los bosques del Pirineo Occidental peninsular en el siglo XVIII. En Varela Gomes, R. e Trapaga Monchet, K. (eds.), Árbores, barcos e homens na Península Ibérica (séculos XVI-XVIII) (pp. 41-54). Lisboa: Instituto de Arqueologia e Paleociências da Universidade Nova de Lisboa.

Aragón Ruano, Á. (2019). Un choque de jurisdicciones. Fueros y política forestal en el Pirineo occidental durante el siglo XVIII. Obradoiro de Historia Moderna, 28, 135-162.

Aranda, G. de (1990). Los bosques flotantes: historia de un roble del siglo XVIII. Madrid: ICONA.

Baudot Monroy, M. (2012). Barcos para el rey. Julián de Arriaga, la madera y la construcción naval, (1752-1754). En García Hurtado, M. (ed.), La Armada española en el siglo XVIII (pp. 297-328). Ciencia, hombres y barcos. Madrid: Sílex.

Bogucka, M. (1968). Handel niderlandzko-gdański w latach 1597-1651 w świetle amsterdamskich kontraktów frachtowych. Zapiski Historyczne, 33, 171-190. 
Bogucka, M. (1962). Zboże rosyjskie na rynku amsterdamskim w pierwszej połowie XVII wieku. Przegląd Historyczny, 53, 118-131.

Díaz Ordoñez, M. (2018). Radiografía de un fracaso angloespañol: el cáñamo, un producto que debería de haber llegado de América durante los siglos XVI-XIX. Obradoiro de Historia Moderna, 27, 263-289.

Díaz Ordoñez, M. (2009). Amarrados al Negocio. Reformismo borbónico y suministro de jarcia para la Armada Real (1675-1751). Madrid: Ministerio de Defensa.

Fernández Flórez, M. (2019). Controversias sobre los usos forestales en Cantabria durante la segunda mitad del siglo XVIII. Obradoiro de Historia Moderna, 28, 163-186.

López Arandia, M. A. (2018). Aprovisionando de madera el arsenal de Cartagena: el proyecto de Manuel Bernia y las flotaciones por el río Segura (1784-1793). Tiempos Modernos, 36, 1, 127-168.

Mączak, A. (1972). Między Gdańskiem a Sundem: studia nad handlem battyckim od potowy XVI do potowy XVII w. Warszawa: PWN.

Martínez González, A. (2013). Bosques y política naval atlántica: las reformas normativas e institucionales de José Patińo (1717-1736). Revista Hispanoamericana, 3, 1-26.

North, M. (1996). The Export of Timber and Timber by Products from the Baltic Region to Western Europe, 1575-1775. En North, M. (ed.), From the North Sea to the Baltic: essays in commercial, monetary and agrarian history, 1500-1800 (pp. 1-14). London: Routledge.

Quintero González, J. (2004). La madera en los pertrechos navales. Provisión de motones, remos y bombas al arsenal de La Carraca. Tiempos Modernos, 4, 10, 1-12.

Reichert, R. (2016). El comercio directo de maderas para la construcción naval española y de otros bienes provenientes de la región del Báltico sur, 1700-1783. Hispania. Revista Española de Historia, 76, 252, 129-157.

Reichert, R. (2019a). ¿Cómo España trató de recuperar su poderío naval? Un acercamiento a las estrategias de la Marina Real sobre los suministros de materias primas forestales provenientes del Báltico y Nueva España (1754-1795). Espacio Tiempo y Forma. Serie IV, Historia Moderna, 32, 73-102.

Reichert, R. (2019b). Recursos forestales, proyectos de extracción y asientos de maderas en la Nueva España durante el siglo XVIII. Obradoiro de Historia Moderna, 28, 55-81.

Rodríguez Hernández, A. J., Arroyo Vozmediano, J. y Sánchez Belén, J. A. (eds.). (2017). Comercio, guerra y finanzas en una época en transición (siglos XVII-XVIII). Valladolid: Castilla Ediciones.

Serrano Álvarez, M. (2013). El poder y la gloria: élites y asientos militares en el astillero de La Habana durante el siglo XVIII. Studia Historica Historia Moderna, 35, 99-125.

Serrano Álvarez, M. (2019). Élites y política en el astillero de La Habana durante el siglo XVIII. Obradoiro de Historia Moderna, 28, 83-104.

Solbes Ferri, S. y Fé Cantó, L. F. (2016). Las estrategias defensivas del Imperio hispánico en el siglo XVIII. El precio de la seguridad. Vegueta: Anuario de la Facultad de Geografía e Historia, 16, 13-30. 
Torrejón Chaves, J. (2000). La madera báltica, Suecia y España (siglo XVIII). En Ramos Santana, A. Comercio y Navegación entre España y Suecia (siglos X-XX) (pp. 163-222). Cádiz: Universidad de Cádiz.

Torres Sánchez, R. (2013). El precio de la guerra. El estado fiscal-militar de Carlos III. Madrid: Marcial Pons.

Torres Sánchez, R. (2016). Military Entrepreneurs and the Spanish Contractor State in the Eighteenth Century. Oxford: Oxford University Press.

Trindade, A. R. (2015). Bourbon naval policy, forestry and timber supply for shipbuilding in Andalusia (1700-1759) brief introductory research notes. En Varela Gomes, R. y M., The management of Iberian forest resources in the Early Modern Shipbuilding: History and Archaelogy (pp. 57-63). Lisboa: Instituto de Arqueologia e Paleociencias.

Valdez-Bubnov, I. (2018). Shipbuilding administration under the Spanish Habsburg and Bourbon Regimes (1590-1834): A comparative perspective. Business History, 60(1), 105-125.

Valdez-Bubnov, I. (2009). War, Trade and Technology: The Politics of Spanish Shipbuilding Legislation, 1607-1728. International Journal of Maritime History, 21, 75-102.

Wing, J. T. (2015). Roots of Empire. Forests and State Power in Early Modern Spain, c. 1500-1750. Leiden-Boston: Brill. 